\title{
EXPERIENCES IN MANPOWER PLANNING FOR GEOMATICS
}

\author{
David Fairbairn \\ School of Civil Engineering \& Geosciences, Newcastle University, NEWCASTLE UPON TYNE NE1 7RU, United Kingdom - \\ david.fairbairn@ncl.ac.uk
}

\section{Midterm Symposium ISPRS Commission VI}

KEY WORDS: cartographic education, manpower planning, employment in geomatics

\begin{abstract}
:
This paper addresses the issue of manpower planning in meeting the needs of national and international economies for trained geomatics professionals. Estimated statistics for the numbers of such personnel, and experience in assessing recruitment into the profession reveal considerable skills gaps, particularly in the mature economies of the developed world.

In general, centralised manpower planning has little official role in western economies. However, informal surveys of shortfalls in supply of qualified graduates in many fields, including geomatics, are undertaken by professional organisations, educational establishments and consultancies. This paper examines examples of such manpower surveys and considers whether more effective manpower planning would ensure a more efficient geomatics industry in a nation, and what the nature of such an exercise should be.
\end{abstract}

\section{INTRODUCTION}

The disciplines of geomatics are in the middle of a revolution in scope, demands, and influence. Fundamental changes to the way in which the technology operates and is used are apparent, whilst the impact of geomatics on society is significantly different to anytime in the previous long history of our subject. Further, scientific demands of, and input into, subjects of surveying, mapping, cartography and remote sensing (all disciplines within the field of geomatics) require an ever broadening mind-set among participants in geomatics activity.

In cartography, specifically, the nature of the field has changed: previously, it was part of a linear workflow-line which encompassed firstly geodesy, then imaging and data capture, before moving into representation and visualisation of the geospatial information, not exclusively derived from topographic observation, but certainly rooted in rigorous spatial frameworks. Today, there are many alternatives to each step in the flow-line, and indeed the flow-line is no longer linear - it can branch, backtrack, circumvent; steps can be followed in very different ways using different procedures, and can sometimes be skipped entirely. This variety, this availability of data, tools, procedures, and this freedom to select and apply them, is what now characterises the work of cartographers and must be reflected in the contemporary education of cartographers.

Further, such education and awareness-raising needs to be extended to those engaged in manpower planning and management of the labour market. Previous manpower planning exercises have been based on outdated knowledge of what the geomatics industry needs from its workforce and what it can supply to clients and public service. Thus, the influence of studies of the subject of geomatics on human resource needs and the use of the labour market is also considered. The identification of 'critical and priority skills' is a typical outcome of such studies, and whilst such outcomes interact with educational syllabus development, they also importantly can feed in to national manpower planning.

\section{EDUCATION AND EMPLOYMENT IN CARTOGRAPHY AND GEOMATICS}

\subsection{Educational developments for effective employment}

The linkage between education and training, and employment in the cartographic and geomatics sector is as clear as it is in other fields of human activity. The technico-scientific nature of the discipline implies that the 'industry' is seeking qualified graduates and apprentices who have followed a focussed curriculum, whilst those engaged in education and training seek to certify that their offerings are appropriate and relevant, ensuring that industry needs are met. The dynamic nature of the field therefore means that educational provision, delivery and curriculum must be addressed alongside issues of employment forecasting, workforce demands and manpower planning.

The development and maintenance of a 'Body of Knowledge' can meet the educational needs of the former, assisting in the development of learning objectives for both specific training courses, and any more general didactic provision in the discipline of cartography. Contemporary debates on, and updates for, curriculum developments associated with the Body of Knowledge, and other educational initiatives, are described in a number of recent and ongoing studies (e.g. Veenendal, 2014). The manpower planning aspect, however, is relatively neglected. This is despite the fact that the supply of a welltrained workforce is regarded as paramount by most progressive corporations and employers (industry, government and research bodies). Fairbairn (2013) concluded that a well-researched 'Body of Knowledge' can assist in determining the scope of education; but that significantly more effort needs to be directed towards manpower planning in the cartographic industry to ensure a meaningful focus for such educational provision.

\subsection{Concepts of manpower planning}

Manpower planning as a human activity can be characterised in two distinct ways: firstly, the epitome of centralised planning, in Stalinist command economies, was typified by Eastern European states in the post-World War II period. Here employment and labour ministries ensured that human resources were directed as needed by the demands of five year economic 
plans and long-term strategic forecasting of supply and demand. Such inflexible centralised allocation of resources can be contrasted with the free market approach which relied on the 'unseen hand' of resource allocation under which the laws of supply and demand, and market economics, would direct individuals, and by extension cohorts of workers, to sectors which had requirements for work to be done.

In reality, these two extreme models were implemented in somewhat modified form. In particular, attempts were made in free market economies to at least predict the employment patterns of the future. Brown, Green and Lauder (2001, p. ix) noted that: "In the post-war era, full employment could be achieved by the Keynesian expedient of manipulating demand ... This strategy met its nemesis in the in the early 1980 s ... Thereafter, a subtle change occurred in political rhetoric from promises of full employment to full employability. Full employability signalled a shift from demand side policies to promote employment to supply-side policies which emphasised individuals' education and skills".

Thus, even for the fully free-market oriented economies of the 1980s and 1990s, subject to a Thatcherite and Hayekian philosophy of economic management, there was a view that personal development in the form of educational and training attainment would allow for individuals to find a place in the ruthless world of employment. And this 'personal development' would allow a citizen to flourish in such developed economies, where planning of any type was regarded as unnecessary state intervention and the adjustment of labour markets was to be done by market forces, only influenced by personal ambition and development.

Manpower planning has been viewed by both command and 'free-enterprise' economies as a means of ensuring more effective, more productive and less wasteful use of human resources. Integrated with national economic, social and political philosophy, some thus believe that manpower planning can actually strengthen market forces, whilst others believe it is an integral part of a socialist economy.

\subsection{Practical approaches to manpower planning}

In fact, even in the most open of free-market, enterprise-driven, cultures, there have always been some attempts to at least monitor the labour market, if not to optimise its outcomes. Intervention becomes more important when a significant amount of state money is spent on the education and training elements of an individual's personal development, which (as has been seen) is a preferred method of developing employment opportunities for 'free-enterprise' cultures.

Thus, medical training is a burden on state finances, even in the most liberal of economies (it uses up institutional resources which cannot be retrieved; its length takes resourceful and intelligent workers out of the national economy for a significant time period; its volume and quality have a direct impact on the (difficult to quantify) health of the citizen), and thus it is no surprise that manpower planning is practiced in such a field.

Crothers, in 2003, for example declared that "Manpower planning in New Zealand over the (previous) few decades ... waxed and waned according to prevailing political ideologies; ... unfashionable for the last decade-and-a-half, it is confined to the health sector (where training is expensive and where manpower crises abound)" (Crothers, 2003).

\subsection{Issues in manpower planning}

So, how does manpower planning actually work? It is difficult to see beyond the so-called 'Delphi approach', which suggests that forecasting in fields such as technology, human activity and policy-making can be most effective by communication of ideas, background, and discipline-expertise, by a group of panellists who can detect trends, judge innovation and predict change. Unfortunately, the results of such an approach are mainly a combination of personal opinions and subjective views, often with little scientific basis as predictions.

Such exercises are normally done at a 'macro'-scale, where a complete national picture is sought, and the major focus is on an aggregate picture across very broadly defined areas of human employment. Quite often a government can abrogate any responsibility for the process of manpower planning (although it often is the only source of the aggregate level data) and an individual company can take the view that its own internal manpower planning is good commercial practice. Such 'human resource planning' is a microcosm of the national exercise, but is often regarded as a sensible way for individual organisations to behave.

Thus, surveys can be undertaken internally by companies trying to optimise their use of their human resources. A similar approach can be adopted by educational establishments who have an interest in assessing the value of a course and qualification to a graduate (and future employee in industry).

\section{MANPOWER PLANNING IN GEOMATICS}

With the demise of centrally-planned economic management in Eastern Europe, the level of manpower planning worldwide has decreased significantly, with most national governments seemingly reluctant to engage in such an intrusive, nation-wide, centralised exercise. For the past two decades, most industrysectors have had to undertake their own assessments of where their discipline and commercial activity stand in terms of the use of human resources.

Even within a broad-ranging discipline such as geomatics there have been remarkably few studies of how the industry is faring - its strengths, weaknesses, opportunities, and threats: the time for an overall SWOT analysis of geomatics as a human activity is long overdue. There are, however, some noteworthy exceptions. A striking calculation from Molenaar (2009) estimates that there are currently 2.5 to 3 million geomaticians employed worldwide: if each has a 40 year career then 75,000 new recruits are needed each year; and if $10 \%$ of the total workforce needs some form of continuing educational provision in order to update, then a further 300,000 students can be counted upon. A significant proportion of these potential geomatics students will be specialist in the large number of different (although overlapping) branches such as measurement science, remote-sensing, cartography etc. This set of estimates was presented in order to demonstrate to the geomatics industry that education and training are vitally important to the future health of the profession, and to assist in making some estimates of the demand for and supply of geomaticians. There are few other such estimates, or studies with a focus on geomatics manpower planning.

Despite the resistance to state-led economic management in the USA, there are interesting and instructive examples of the quantitative assessment of labour patterns and market sectors in 
that country, along with efforts to optimise the personal development which, we have seen, is the foundation to employability for free-enterprise cultures. The United States Department of Labor has a long-standing interest in reporting on and improving the American labour market. In 2010 it released its Geospatial Technology Competency Model (accessible

through http://www.careeronestop.org/competencymodel/) aiming to give potential employees a fairly prescriptive overview of the skills required to successfully enter the geomatics sector.

Whilst not giving specific instruction about employment rates and numbers within sectors in geospatial technologies, the model is quite detailed in its coverage of expected skills, background abilities, and professional standing of expected entrants into the geospatial profession, and thus has an influence on the way in which the workforce in areas such as cartography and other geospatial sciences can be directed and managed.

Further north, a decade ago, the Canadian government, through its Department of Human Resources and Skills Development commissioned an extraordinarily comprehensive Human Resources Study on the Geomatics Sector of the Canadian Economy (CCLS et al., 2001). Prepared by learned and professional organisations in the Canadian geomatics arena, this report covered a wide range of issues, including description of the disciplines within geomatics (including cartography), the nature of the industry (both inside Canada and also how well Canadian geomatics works overseas) and a thorough review of the technology currently used and how it would develop in the future. Two further extensive sections of the report describe education and training in geomatics in Canada, and the human resources profile. A survey of geomatics activities showed expected increases in activity in all sectors in the 2001-2006 period, but some, including photogrammetry, geodesy, cartography and land surveying, were expected to increase at a slower rate than other areas such as navigation, GIS, decision support and consulting. The overall rate of growth led the survey to estimate a need for two thousand university graduates in geomatics by the year 2004, compared to an estimated supply of 950 at the time of survey in 2001. In retrospect, of course, this was an underestimate and, particularly in cartography, a more vibrant sector would require an even greater increase in trained personnel during the first decade of this century: the survey was not able to foresee the extraordinary growth in several sub-disciplines of cartography now central to the contemporary common everyday work of a geomatics professional. The continuing expanding demand for experienced cartographic data handlers in internet cartography, web mapping, location-based services (LBS), spatial data infrastructures (SDI), sensor networks, and augmented reality is increasing even more, exposing the continuing need to skills to meet market demands.

The final example of manpower planning and labour market analysis presented here is more contemporary, and does take into account the rapid developments of the geomatics disciplines. A 'Final Report' on manpower strategies published by the Botswana Training Authority in 2010 (BOTA, 2010) was commissioned to "forecast and identify a list of priority vocational skills and develop strategies to fast track priority skills development". Its comprehensive overview of the national economy, the health of market sectors, the basic methodology adopted to data collection and skills forecasting, and the list of critical and priority skills, mark this report out as a document of considerable importance. One particular outcome of interest is that even in a nation with a population as low as Botswana's (just over 2 million in 2011), there is an estimated shortfall of over 3,000 educated and trained geomaticians by the year 2016 (Table 1). It is incumbent on those who are educating geomaticians to ensure that provision is made to match such needs both in this country and throughout the world. And it is clear that some formal assessment of the labour market in this way is needed to ensure the continued vitality of the geomatics profession, and interest in the disciplines of geomatics as viable professions for substantial numbers of the national workforce to consider entering.

Professional organisations in geomatics, and large employers of geomaticians in industry and government should be urged to produce national overviews of manpower requirements for our discipline, and to ensure that such overviews are translated, through government policy, into practice. The provision and take-up of educational programmes in geomatics is dependent on the perception of need for geomaticians within a national economy; and there is a corresponding need in industry and government for there to be a supply of trained and educated geomaticians to meet that need.

\section{FURTHER ISSUES}

A major aim of manpower planning is to determine such skills gaps which need to be filled to improve the efficiency of national economy. Mismatches at a national level between the market supply of qualified personnel and the requirements of industry, commerce and government administration can be filled in two ways: firstly, a country can rely on attracting a number of qualified immigrants; or measures can be put in place to improve the employability and skills of the current student body and the existing workforce.

The major problem of the first of these is the negative effects on developing economies, and a reliance on expatriate communities of guest workers. The problems of a 'brain drain' whereby the most experienced, well-qualified, and ambitious products of a country's educational system are attracted by high rewards overseas, have long been felt by populous countries such as Egypt and Pakistan.

The market for expatriate workers relies on a supply- and demand-adjusted set of rewards and remuneration which normally ameliorate the disturbance caused to the domestic life of those involved. But 'quality of life' factors can often have a confounding effect on the free market for labour, as workers can opt for a lifestyle and work-life balance which does not maximise their economic reward. Future prospects, promotion possibilities, support for training, and intangible factors such as job satisfaction, also each affect the employment market and the workforce in unpredictable ways.

The market for staff can be significantly influenced by the prevailing balance between the private and public sectors within a national economy, and indeed within an industry sector. Theoretically, the results of effective manpower planning will be more obviously felt within those industries and activities controlled by government policy, and when governments have control over the workforce employed by them. However, private companies may actually have a more responsive and flexible approach to employment with an ability 
Table 22: Labour Demand and Supply by training-2005-2016 and skills gap

\begin{tabular}{|c|c|c|c|c|c|c|c|c|c|c|c|c|}
\hline Training Programme & Employed & Unemployed & $\begin{array}{l}\text { Total } \\
\text { Trained }\end{array}$ & LD 2009 & LD 2016 & $\begin{array}{l}\text { Total stock } \\
\text { to } 2009\end{array}$ & Gap 2009 & $\begin{array}{c}\text { Growth } \\
\text { rate supply }\end{array}$ & $\begin{array}{l}\text { Addition } \\
\text { supply } \\
\text { (2010:-16] }\end{array}$ & $\begin{array}{c}\text { Total } \\
\text { Supply } \\
2016 \\
\end{array}$ & $\begin{array}{l}\text { Skills Gap } \\
2016\end{array}$ & $\begin{array}{l}\text { Annual } \\
\text { Supply }\end{array}$ \\
\hline $\begin{array}{l}\text { Business/Commercial Admînistration } \\
\text { Courses }\end{array}$ & 3951 & 2262 & 6213 & 6718 & 56285 & 12408 & -5690 & 0.89 & 77302 & 89710 & -33425 & -4775 \\
\hline Tourist Trade Programs & 602 & 810 & 1412 & 1024 & 8579 & 2582 & -1558 & 0.93 & 16809 & 19391 & -10812 & -1545 \\
\hline Crop Breeding/Husbandry Programs & 42 & 0 & 42 & 72 & 600 & 507 & -435 & 0.18 & 639 & 1146 & -546 & -78 \\
\hline Livestock Management Programs & 169 & 208 & 377 & 287 & 2404 & 1121 & -834 & 0.19 & 1491 & 2612 & -208 & -30 \\
\hline Public Health/Sanitation Programs & 88 & 47 & 135 & 149 & 1249 & 543 & -394 & 0.12 & 456 & 999 & 250 & 36 \\
\hline Technical/Vocational Teacher Traîning & 68 & 0 & 68 & 115 & 965 & 323 & -208 & 0.15 & 339 & 662 & 303 & 43 \\
\hline Christian Religion and Culture courses & 71 & 145 & 216 & 121 & 1010 & 91 & 30 & 0.12 & 76 & 167 & 842 & 120 \\
\hline $\begin{array}{lrrr}\text { Other Electronics } & \text { Programs } & \text { incl. } \\
\text { Telecommunications } & & \\
\end{array}$ & 147 & 158 & 305 & 250 & 2094 & 202 & 48 & 0.21 & 297 & 499 & 1595 & 228 \\
\hline Forestry Programs & 273 & 181 & 454 & 465 & 3895 & 500 & -35 & 0.18 & 76 & 576 & 3318 & 474 \\
\hline Shoe making/Leather Trades training & 243 & 144 & 387 & 413 & 3461 & 16 & 397 & 0.11 & 12 & 28 & 3433 & 490 \\
\hline $\begin{array}{l}\text { Drafting, Surveying \& Cartographic } \\
\text { Course }\end{array}$ & 293 & 168 & 461 & 498 & 4174 & 255 & 243 & 0.26 & 464 & 719 & 3455 & 494 \\
\hline Flestrician Prngrams & 123.3 & 432 & 1655 & 2079 & 17416 & 4043 & -1964 & ก.ร & 7358 & 11401 & 6014 & 859 \\
\hline
\end{tabular}

Table 1: Extract from BOTA (2010) showing the estimated 'skills gap' in employment fields in Botswana by 2016

\begin{tabular}{|c|c|c|c|c|}
\hline Qualification Field & $\begin{array}{c}\text { Level of } \\
\text { Qual. Scale }\end{array}$ & Total & $\begin{array}{r}\text { Ave. } \\
\text { Income }\end{array}$ & Ave. Age \\
\hline Natural and Physical Sciences not further define & 5.2 & 27087 & 38472 & 40.4 \\
\hline Mathematical Sciences & 5.1 & 13173 & 42145 & 42.6 \\
\hline Physics and Astronomy & 5.6 & 5358 & 45071 & 43.8 \\
\hline Chemical Sciences & 5.4 & 13083 & 42076 & 44.8 \\
\hline Earth Sciences & 5.6 & 5703 & 41323 & 40.9 \\
\hline Biological Sciences & 5.6 & 27258 & 34494 & 38.6 \\
\hline Other Natural and Physical Sciences & 4.1 & 9351 & 34004 & 39.0 \\
\hline Information Technology not further defined & 3.6 & 1947 & 32853 & 31.2 \\
\hline Computer Science & 2.9 & 32976 & 28438 & 32.0 \\
\hline Information Systems & 4.2 & 12975 & 34561 & 31.8 \\
\hline Other Information Technology & 11 & 108 & 21410 & 355 \\
\hline Engineering and Related Technologies not further defined & 2.8 & 29340 & 40237 & 45.2 \\
\hline Manufacturing, Engineering and Technology & 1.7 & 25704 & 31058 & 45.1 \\
\hline Process and Resources Engineering & 3.7 & 8010 & 44149 & 43.9 \\
\hline Automotive Engineering and Technology & 1.9 & 64767 & 32382 & 43.2 \\
\hline Mechanical and Industrial Engineering and Technology & 2.3 & 52560 & 39292 & 43.5 \\
\hline Civil Engineering & 4.7 & 15543 & 50579 & 45.2 \\
\hline Geomatic Enqineering & 3.9 & 4413 & 47893 & 45.9 \\
\hline Electrical and Electronic Engineering and Technology & 2.7 & 68616 & 41794 & 44.0 \\
\hline Aernsnare Fnnineerinn and Terhnnlnav & $3 \cap$ & 10731 & $\triangle 6 \Delta 81$ & $\Delta 51$ \\
\hline
\end{tabular}

Table 2: Sector based labour market statistics (relative entry-level qualification; number of employees, average annual income (in NZ dollars); average age) from a survey of New Zealand employment 2002 (from Crothers, 2003)

to more quickly respond to short-term variation in demands for labour.

Adjustment of supply of well-qualified staff to such short term demands is affected by recruitment policies which can often prioritise project-by-project employment of staff over longer term retention of key personnel. And the definition of 'key personnel' can vary, as the market in geomatics for technical staff may, or may not be, more vital than that for professional scientific staff.

A further constraint on the free working of a liberal labour economy is the existence of, and value placed upon, licencing and accreditation of professionals in a large number of disciplines. Geomatics is no exception, as there is a large number of professional and institutional bodies which aim to regulate and restrict the workforce and the patterns of activity within the field. Whilst such licencing may be written into law as a statutory requirement for the efficient and safe operation of the profession, such arrangements do have an effect on the numbers, quality and rewards of those who practice, and make accurate predictions of supply and demand of personnel more difficult to manage.

Related to such constraints on supply and demand is the impact of educational and training facilities and opportunities on the labour market. Effective manpower planning cannot be undertake without reference to those institutions preparing workers for the profession, and those engaged in continuous 
professional development to ensure continued capacity of the workforce to respond to the demands for its services.

In its traditional sense, manpower planning has been directed towards using the human resource as effectively as possible within a national economy. In terms of measurable achievement, the most straightforward way in which to assess such effectiveness has been to quantify productivity using standard measures such as output, gross domestic product, and added-value statistics. Such metrics inevitably concentrate on the calculable results of actually producing 'something'. It is clearly much more difficult to quantify less tangible outputs such as research activity, public service, or national administration. As much geomatics activity falls into such categories, the ability to assess the impact of geomatics on the national economy is limited, and the consequent level of impact of manpower planning in this field is also difficult to ascertain.

\section{CONFLATING MANPOWER STUDIES}

One of the few studies which looked at many of such issues together was reported by Crothers who studied the New Zealand economy in 2003. Table 1 (extracted from Crothers, 2003) shows that whilst the average salary of a geomatic engineer is relatively high, one reason may be that the average age of such an employee in this sector is also well above average. Such figures have likely changed in the past 10 years, but anecdotal evidence shows that geomatics is still perceived as an ageing profession, with younger entrants into the profession often categorising themselves as something other than a 'geomatician'. The study by Crothers also indicated that the level of qualification on entry had some variability: in fact, he identified computer science and land-based professions as having a bifurcated pattern of entry-level qualification, with some with advanced study at $\mathrm{PhD}$ level employed alongside those with low levels of school-leaving achievement.

\section{CONCLUSION}

Demands on the geomatics industry worldwide are pressing: there are continuing global challenges in the future which must be met with reliance on the skills, experience and imagination of well-educated cartographers and geomaticians. It is important to make sure that there are sufficient numbers of such educated and trained people able to work in these areas. How this aim is successfully achieved is difficult to formulate: with the demise of command economies and their associated national economic planning, it seems that we must fall back onto the more laissez faire methods which concentrate on individual career planning and personal development. Such an approach has ramifications for education and training provision in geomatics, and efforts must be maintained to raise awareness in the general population, recruit and retain qualified staff, and promote career development.

\section{REFERENCES}

BOTA 2010, Final Report, Botswana Training Authority, Gaborone. 224pp.

Brown, P., Green, A., and Lauder, H. 2001. High Skills: Globalization, Competitiveness and Skill Formation, Oxford University Press, Oxford.

CCLS (Canadian Council of Land Surveyors), Canadian Institute of Geomatics (CIG), and Geomatics Industry Association of Canada (GIAC) 2001. Geomatics Sector, Human
Resources Study, Human Resources Development Canada, Ottawa. 372pp.

Crothers, C. 2003. The degree of fit: the future relationship between qualifications and jobs in New Zealand, in Learning for an unknown future, Proceedings of the $26^{\text {th }}$ HERDSA Annual Conference, Christchurch, New Zealand, 6-9 July 2003.

Fairbairn, D. 2012. Candles for Cartography: Helping to Illuminate our Discipline. Keynote address at GeoCart2012 (ICA Regional Symposium for Australia and Oceania), Auckland, New Zealand.

Fairbairn D. 2013. Issues in cartographic education: how and how many? in Buchroithner, M., Prechtel, N. and Burghardt, D. Cartography from Pole to Pole: Selected Contributions to the XXVIth International Conference of the ICA, 461-470

Molenaar, M. 2009. Cross Border Education for the Global GICommunity. Keynote speech at the 24th International Cartographic Conference, Santiago de Chile, November 2009.

Veenendaal, B. 2014, Addressing the challenges of a Quarter Century of GIScience Education: a flexible higher education curriculum framework. ISPRS Commission VI mid-term symposium, Wuhan. China. 